\title{
Analysis of bearings behaviour with cylindrical rollers with variable center of gravity
}

\author{
Sorin Barabas ${ }^{1, *}$ and Adriana Florescu ${ }^{1}$ \\ ${ }^{1}$ Transilvania University of Brasov, Faculty of Technological Engineering and Industrial \\ Management, Department of Engineering and Industrial Management, Romania
}

\begin{abstract}
This paper consists in analysis of the contact stress and deformations appeared to the cylindrical rollers with variable center of gravity who equips large bearings, with finite elements method. Also it proposed an innovative model of lubrication system mounts in the hollow cylindrical rollers of the large bearings where it is stored the lubricant who is driven to the raceways through holes fitted with closing/opening systems made in the cover, controlled by a command system, monitoring and control, equipped with temperature sensors and wireless command. Elimination of lubricant, in stages, leads to changes in position of center of gravity of roller, thus to change its behavior in functioning. Comparison of deformations occurred in cylindrical rollers, solid, with hollowness, and with variable center of gravity, allow favorable conclusions, on the implementation of the proposed lubrication system.
\end{abstract}

\section{Introduction}

Suitable bearings lubrication minimize wear, increase their lifetime significantly, and makes possible rolling processes. Using large bearings in wind power assemblies, which have permanent operation in difficult conditions with high variability of both, the load and speed, is a problem widely studied because of difficulties arising. The importance of developing green energy, increasing the energy efficiency of wind power plants and their wide distribution, turn maintenance process, therefore, the lubrication process, a matter of great importance.

The possibility of using hollow rollers in large bearings construction, allows the development of a new lubrication system, automated, controlled, and managed by computer, placed in the cavity of rollers.

To improve efficiency of lubrication, it is necessary to maintain the lubricant film thickness to constant values, the amount of lubricant introduced to the raceways being strictly controlled and in accordance with the lubricant consumed or evacuated. Lubrication process is influenced by temperature, rotation speed, geometry of raceway, static and dynamic loads, type and quantity of lubricant. All these factors determine the quality of process with consequences on lifetime and efficiency of energetic assembly.

\footnotetext{
* Corresponding author: sorin.barabas@unitbv.ro
} 
Contacts of rolling elements has the following possibilities for interaction [1]: contact elastohydrodynamic, mixed frictional contact, wear contact and contact with presence of particles between the surfaces.

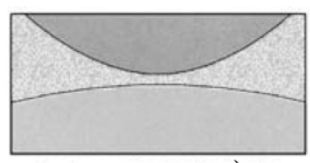

a)

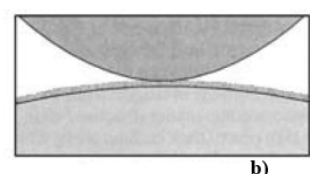

b)
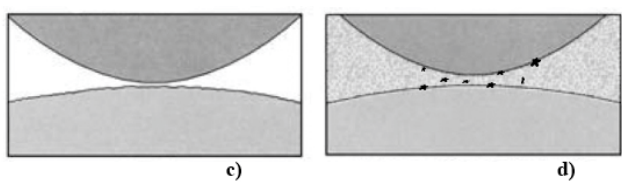

Fig. 1. Contacts of rolling elements a) elastohydrodynamic, b) mixed, c) wear contact, d) contact with particles between the surfaces.

The amount of lubricant can be calculated by the formula:

$$
Q_{l}=f_{v}\left[\rho_{b} \frac{10^{-3} \pi T\left(D^{2}-d^{2}\right)}{4}-\frac{m_{b}}{7,8 * 10^{-3}}\right]
$$

where: $\quad \mathrm{Q}_{1}$ is lubricant quantity[N];

$\mathrm{f}_{\mathrm{v}}$ is a parameter who depends by rotation speed (approx. 0,3 ..0,5);

$\rho_{\mathrm{b}}$ is bearing steel density;

$\mathrm{T}$ is bearing width $[\mathrm{mm}]$;

$\mathrm{D}$ is exterior diameter [mm];

$\mathrm{d}$ is interior diameter $[\mathrm{mm}]$;

$\mathrm{m}_{\mathrm{b}}$ is bearing mass $[\mathrm{kg}]$.

The contact stress and the deformations occurred in the contact zone, between roller and raceway, strongly influence the lubrication film. The elastohydrodynamic theory $[2,3,4]$ uses, for calculation of thickness of lubrication film, the point contact equation (Hamrock and Dowson, equation (2) ) and line contact equation (Dowson, equation (3) ). (Figure 2.).

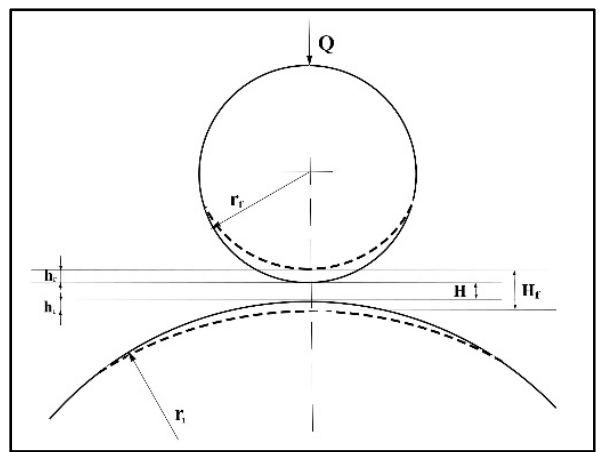

Fig. 2. The influence of deformations on thickness of lubricant film

$$
\begin{gathered}
H=3.63 U^{0.68} G^{0.49} W^{-0.073}\left(1-e^{-0.68 k}\right) R_{r} \\
H=2.65 U^{0.68} G^{0.54} W^{\prime-0.13} R_{r}
\end{gathered}
$$

where: $\quad H$ is minimum lubricant thickness [mm];

$\mathrm{U}$ is a speed parameter who depends by rotation speed and lubricant viscosity;

$\mathrm{G}$ is material parameter;

$\mathrm{W}, \mathrm{W}$ ' are load parameters for point contact and line contact;

$\mathrm{k}$ is a parameter who depends by contact area;

$\mathrm{R}_{\mathrm{r}}$ is curvature between roller and raceway [mm];

$\mathrm{h}_{\mathrm{r}}, \mathrm{h}_{\mathrm{i}}$ are deformations in roller and inner ring [mm]

The elastohydrodynamic theory and the theory of linear elasticity $[5,6]$ was used for modelling the process of lubrication 


$$
H r=\frac{1}{\pi}\left(\frac{1-v_{I}^{2}}{E_{I}}+\frac{1-v_{I I}^{2}}{E_{I I}}\right) \iint_{x}^{y} \frac{p(\xi \cdot \eta)}{\sqrt{(x-\xi)^{2}+(y-\eta)^{2}}} d \xi d \eta
$$

where: $\quad \mathrm{H}_{\mathrm{r}}$ is distance between surfaces ;

$E_{I}, E_{I I}$, are Young modulus for each bodies in contact; $v_{I}$ and $v_{I I}$ are Poisson's ratio for each bodies in contact; $p(x, y)$ is the pressure of the common area.

$$
\begin{gathered}
\int_{x}^{y} p(\xi . \eta) d \xi d \eta=\frac{d Q_{d}}{d t} \\
\frac{d Q_{d}}{d t}=\frac{d\left(Q+Q_{s}\right)}{d t}
\end{gathered}
$$

where: $\quad Q_{d}$ is dynamic load $[N]$;

$\mathrm{Q}$ is normal load of bearing $[\mathrm{N}]$;

$\mathrm{Q}_{\mathrm{s}}$ is load due to the weight of lubricant stored in hollow roller.

Application of equilibrium equation (5) and and variability equation of gravity center of roller in relation to time (6) in integral equation of elastic contact, Boussinesq - Flamant (4) allows the analysis of stresses and strains in relation to time. The condition for elastohydrodynamic contact is $\mathrm{H}_{\mathrm{r}}>\mathrm{H}$.

\section{Proposed concept for automated lubrication system mounted in hollow rollers of large bearings}

The concept of automated lubrication implemented for hollow rollers equipping large bearings installed in wind power plants presents the latest fundamental elements of innovation consisting of positioning inside the hollow roller of an automated system equipped with control unit, temperature sensors, opening / closing module of the area with lubricant, wireless transmitter to the computer, power supply and monitoring software, command and control of the functional parameters of the bearing [7].

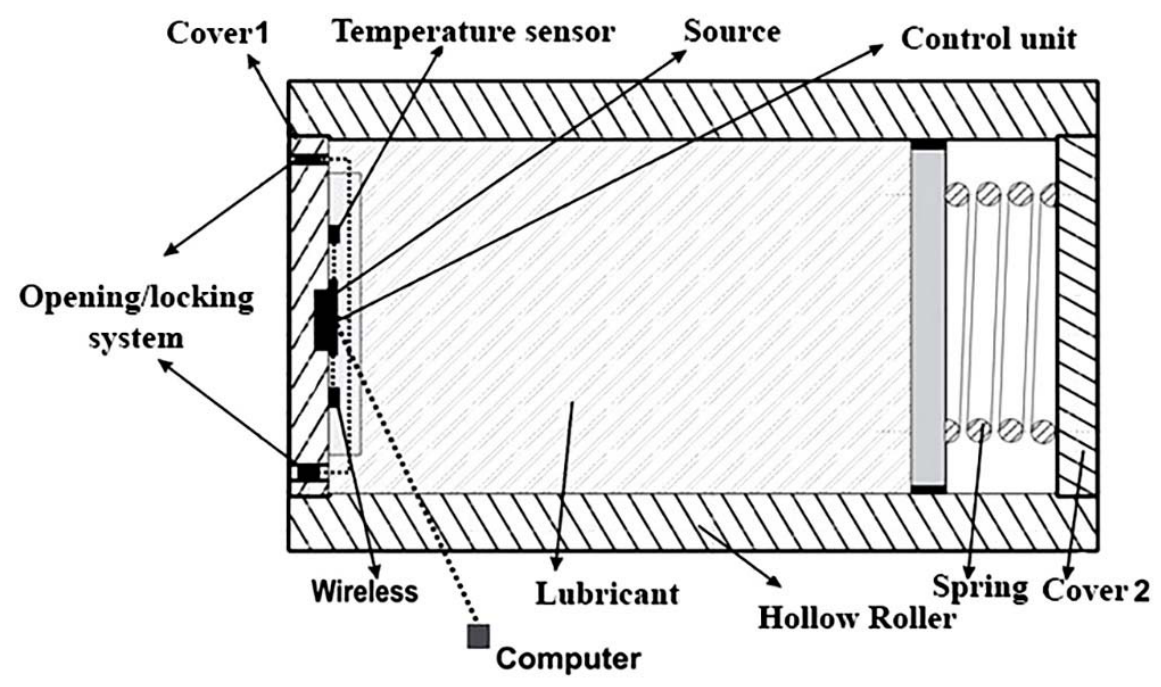

Fig. 3. New concept for automated lubrication system

In Figure 3 it can be seen the proposed lubrication system scheme, following that research conducted during the project to establish the exact design and operation of each module. Thus 
the locking - unlocking system may comprise electrically operated valve or thermal or magnetic operated closing valves.

The source can be a sustainable battery or carbon brushes. The control unit can be programmable or programmed. The assembly may be inside or outside of the roller.

When opening the valves, the lubricant liquid is pushed toward the runways, driven by the piston spring mounted under pressure. In the roller a shift of the centre of gravity occurs which can lead to the appearance of further tensions in the contact areas.

\section{Stress and deformations analysis with Finite Element Method for bearings equipped with proposed lubrication system}

Stress analysis by finite element for bearings with hollow roller wit variable center of gravity, due to lubricant evacuation consists in application of equations (4) and (6) in Nastran software.

Were chosen rollers with $\mathrm{D}_{\text {ext }}=120 \mathrm{~mm}$ and $\mathrm{L}=240 \mathrm{~mm}$. Material of roller is $15 \mathrm{NiCr} 13$ carburized at 63HRC. The diameter of bearing is $\mathrm{D}_{\text {rul }}=2100 \mathrm{~mm}$. For the inside diameter (hole diameter) were chosen four cases according to the following values: solid roller, hollow roller $\mathrm{Di}_{3}=90 \mathrm{~mm}$ with cavity filled with lubricant, with cavity without lubricant and with half of the quantity of lubricant. For bearing with solid rollers and for bearings with hollow rollers with different quantity of lubricant was made the finite element analysis.

When applied finite element analysis method to rollers, was used iteration cinematic method, that assumes that the nodal forces are known by evenly distributing, remaining to calculate the contact forces. The value of these forces is determined by successive iterations resulting when the speed of the node is null.

The results obtained by applying the finite element method were calculated in the position of maximum stress when the loading force is perpendicular to roller. Redistributed components of normal loading force is considered lower, in the angular positions, without influencing the results [8-10].

It was considered the case of normal loading with value $\mathrm{Q}=280 \mathrm{kN}$. For analyzed bearing the loading per hollow roller is $8 \mathrm{kN}$ and for the study cases total loads are $\mathrm{Q}_{1}=308 \mathrm{kN}, \mathrm{Q}_{2}$ $=285.25 \mathrm{kN}, \mathrm{Q}_{3}=282.45 \mathrm{kN}, \mathrm{Q}_{4}=280 \mathrm{kN}$

Table 1: The values of contact elements

\begin{tabular}{|c|c|c|c|c|c|}
\hline Type & $\begin{array}{c}\text { Loads } \\
(\mathrm{kN})\end{array}$ & $\begin{array}{c}\text { Contact } \\
\text { pressure } \\
\left(\mathrm{N} / \mathrm{mm}^{2}\right)\end{array}$ & $\begin{array}{c}\text { Contact lenght } \\
(\mathrm{mm})\end{array}$ & $\begin{array}{c}\text { Von Mises stress } \\
\left(\mathrm{N} / \mathrm{mm}^{2}\right)\end{array}$ & $\begin{array}{c}\text { Deformation } \\
(\mathrm{mm})\end{array}$ \\
\hline 1 & 308 & 2402.4 & 0.5934 & 1039.5 & 0.0199 \\
\hline 2 & 285.25 & 2406.5 & 0.6581 & 1041.9 & 0.0226 \\
\hline 3 & 282.45 & 2410.6 & 0.7512 & 1046.2 & 0.0231 \\
\hline 4 & 280 & 2412.8 & 0.7612 & 1049.7 & 0.0252 \\
\hline
\end{tabular}

1-solid roller; 2-hollow roller $\left(\mathrm{D}_{\mathrm{i}}=90 \mathrm{~mm}\right.$, filled with lubricant); 3-hollow roller $\left(\mathrm{D}_{\mathrm{i}}=90 \mathrm{~mm}\right.$, half filled); 4- hollow roller $\left(\mathrm{D}_{\mathrm{i}}=90 \mathrm{~mm}\right.$, empty); 


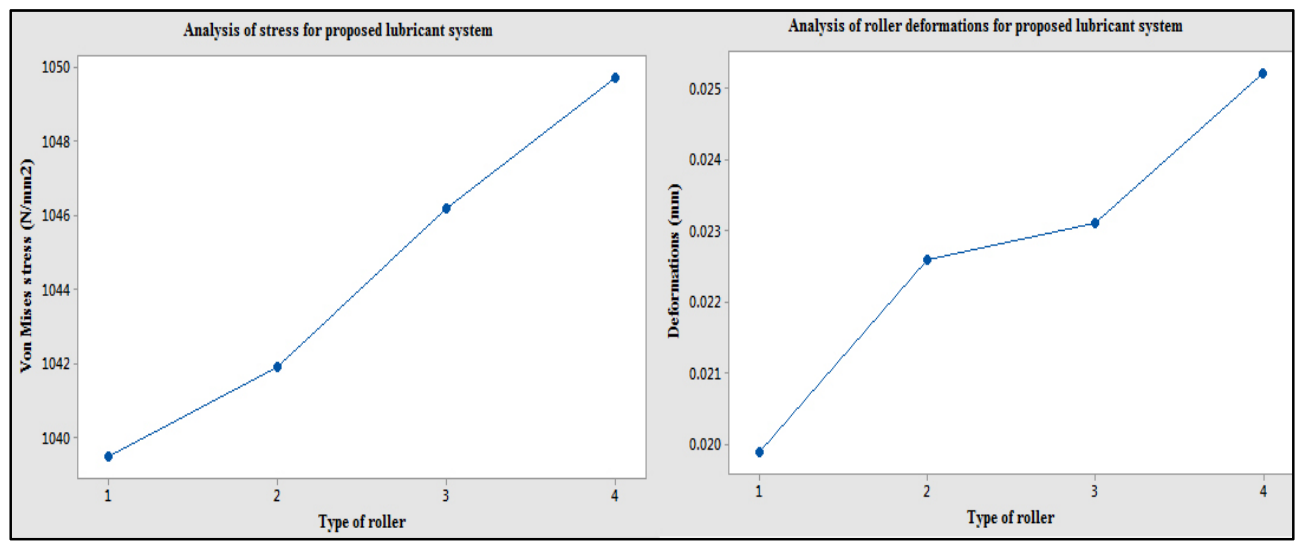

Fig. 4. Graphical analysis for stress and deformations in case of lubricant system for large bearings with hollow rollers

An analysis made on the results (Figure 4), clearly shows slight increase of stresses and deformations with evacuation of lubricant to raceways. The results are interesting from another point of view, namely that advantages of using of hollow rollers, completely reduces the disadvantage of increasing Von Mises stress and deformations.

\section{Conclusions}

The paper also proposed a hollow roller for large bearing having in cavity an automated lubricant evacuation system, to the raceways of the bearing. With the evacuation of lubricant is shown a displacement of the center of gravity rollers, which can cause in system additional wear, who requires a dynamic computing for new stresses occurred on the runways. Finite element analysis performed with Nastran program revealed a slight increase in tensions and strains, insignificant for the modification the thickness of film of lubricant, between roller and raceway. From the research done, lubrication system proposed shows the complete novelty, such as placing it in hollow roller, the lubricant injection system, monitoring, control and its command. The behavior of hollow rollers with lubrication system implemented is identical, differences in stress and strain being negligible, with the maximum deformation of the solid roller $0.025 \mathrm{~mm}$, and the change in center of gravity causes deformations increase only, with 2 microns. Results that implementation of the proposed lubrication system bring significant benefits.

\section{References}

1. F. J. Ebert, Chi. J. Aer., 23, 122 (2010)

2. E.V. Zaretsky NASA Tec.Mem., 102575, (1990)

3. K. Bobzin, T. Brogelmann, Sur. \& Coat. Tec., 290, 100 (2016)

4. B. J. Hamrock, D. Dowson, ASME JOT, 98, 375 (1976)

5. G. Nijebanning, C. H. Venner, H. Moes, Wear J., 176, 217 (1994)

6. M.Y. Panovko, Prob. Mash. i Mash. 5, 54 (2009)

7. S. A. Barabas, A. Florescu, Rev. Rec. 43, 138 (2014)

8. E. Mermoz, D. Fages, L. Zamponi, J. M. Linares, J. M. Sprauel, CIRP. Man. Tec, 65, 157 (2016)

9. V. Liqin, C. Li, Z. Dezhi, G. Le, Chi. J. Aer., 21, 86, (2008)

10. Y. Wei, R. Balendra, J. Mat. Proc. Tec., 145, 233, (2004) 